\title{
Acid catalyzed alkylation of phenols with cyclohexene: Comparison between homogeneous and heterogeneous catalysis, influence of cyclohexyl phenyl ether equilibrium and of the substituent on reaction rate and selectivity
}

\author{
L. Ronchin*, A. Vavasori, L. Toniolo \\ Department of Molecular Science and Nanosystems, University Ca' Foscari of Venice, Dorsoduro 2137, 30123 Venice, Italy
}

\section{A R T I C L E I N F O}

\section{Article history:}

Received 1 August 2011

Received in revised form

28 November 2011

Accepted 7 December 2011

Available online 16 December 2011

\section{Keywords:}

Acid catalysis

Sulfonated resins

Phenols alkylation

Alkylation selectivity

\begin{abstract}
A B S T R A C T
The reactivity of several phenols toward liquid phase alkylation with cyclohexene in the presence of heterogeneous and homogeneous acid catalyst at $358 \mathrm{~K}$ is studied. The comparison between Amberlyst 15 and $\mathrm{CH}_{3} \mathrm{SO}_{3} \mathrm{H}$, as examples of heterogeneous and homogeneous systems, shows a higher activity of the former with different behavior of selectivity between the two systems, anyway, in both systems O-alkylation and ring alkylations occur. A remarkable difference in the selectivity of the ring alkylation between heterogeneous and homogeneous systems is observed: Amberlyst 15 shows a constant ortho/para ratio close to 2, while in the presence of $\mathrm{CH}_{3} \mathrm{SO}_{3} \mathrm{H}$ ortho/para is variable from 3 to 5 , suggesting an involvement of the cyclohexyl phenyl ether rearrangement. This is proved also by a direct relationship between the ortho/para ratio and the concentration of the cyclohexyl phenyl ether when $\mathrm{CH}_{3} \mathrm{SO}_{3} \mathrm{H}$ is used as a catalyst. The formation of cyclohexyl aryl ethers is reversible; on the contrary, ring alkylation appears irreversible. The reactivity of the dimethylphenols shows a strong influence of the steric hindrance of the substituent on the electrophilic attack of the cyclohexyl cation, which is poorly influenced by the inductive effect of the methyl group.
\end{abstract}

(C) 2011 Published by Elsevier B.V.

\section{Introduction}

Organic industrial processes employ acid catalyzed reactions such as alkylation, acylation, isomerization, cracking, nitration, condensation, esterification, etc. The green technologies in order to replace the traditional polluting mineral acid catalysts with solid ones are continuously improved [1-6]. Zeolites, acid treated clays, ion exchange resins and supported acids are investigated by several researchers for their application in pharmaceutical, perfumery, agro-chemicals, dye-stuffs, intermediates and specialty chemical industries [5-12]. Alkylation reactions in particular are really important in the industrial synthesis of many large scale production compounds [11,12].

Alkylation of phenol with cyclohexene has attracted considerable interest because of its industrial and academic relevance [13-21]. This reaction leads to a variety of products such as 4-cyclohexylphenol, 2-cyclohexylphenol, and cyclohexyl phenyl ether depending on both the catalyst and the reaction conditions. The use of solid acid catalysts appears a suitable alternative to the usual procedures in homogeneous phase with catalysts such as $\mathrm{AlCl}_{3}, \mathrm{BF}_{3}, \mathrm{TiCl}_{4}, \mathrm{HF}$. On considering the current effort toward

\footnotetext{
* Corresponding author. Fax: +39 0412348517.

E-mail address: ronchin@unive.it (L. Ronchin).
}

process innovation aimed to avoid environmental concerns, ionexchange resins appear to be ideal catalysts to convert polluting processes into greener ones [2-6].

In a large number of industrial processes the cation-exchange resins are used as a catalyst such as in MTBE or TAME synthesis, the manufacture of alkyl phenols and bisphenol A, the esterification of a variety of carboxylic acids, the hydration of alkenes, the dimerization of isobutene, etc. [4-6,19,22,23].

The mechanism of acid catalyzed alkylation is well known for a long time and it is widely accepted the carbonium ion attack to the electronic rich center as the key step of the reaction $[24,25]$. Cyclohexene in the presence of acid gives the cyclohexyl cation as a transient species that readily reacts with a nucleophile giving the corresponding cyclohexyl derivative. The rearrangement to the more stable methyl cyclopentyl cation occurs only in a negligible extent since the skeleton rearrangement is slower than the nucleophilic attack, which occurs, for many nucleophiles, at encounter [26].

The study of Richard and coworkers on the reactivity of phenol as nucleophile toward methyl phenyl carbocation showed that the relative rates for alkylation of phenol at $-\mathrm{OH}, \mathrm{C}-4$ and $\mathrm{C}-2$ are 230:20:1, respectively. On the contrary, the alkylation of the corresponding nucleophilic sites of phenoxide ion, which is an encounter reaction, showed the relative rates of 2:2:1 [27]. Other authors pointed out that the selectivity toward the ortho position in the 
phenol alkylation is favored when the less hindered secondary carbonium ions are the electrophiles, while tertiary carbocations give prevalently para alkylation $[28,29]$. The studies of Sharma and coworkers, carried out in the early ninety relating the reactivity of phenol in the presence of sulfonated resins, pointed out that the ortho-para selectivity in the ring alkylation of phenol is strictly related to the nature of the olefin employed. In particular, propene and 1-butene give an ortho-para ratio close to 2, while isobutene, $\alpha$-methyl styrene and diisobutene give almost exclusively para alkylation [29]. Recently, Bhatt and Patel reported that supported 12-tungstosilicic acid catalyzes only ring cyclohexylation of phenol giving an ortho-para ratio close to 2 [15]. More recently, Hölderich and coworkers showed that high para selectivity is obtained in the alkylation of phenol with isobutene in the presence of catalysts with Lewis or Brønsted acid sites, indifferently. The selectivity is not sensible to the type of acid present in the catalyst but the activity is influenced by the amount and the strength of the sites [30].

The comparison of activity and selectivity between heterogeneous and homogeneous $\mathrm{BF}_{3} / \mathrm{SiO}_{2}$ and $\mathrm{BF}_{3} \cdot\left(\mathrm{H}_{2} \mathrm{O}\right)_{2}$ catalysts was studied by Clark and coworkers [21]. They pointed out that cyclohexyl phenyl ether, and cyclohexyl phenols are formed in the presence of both systems, but only by the homogeneous $\mathrm{BF}_{3} \cdot\left(\mathrm{H}_{2} \mathrm{O}\right)_{2}$ as a catalyst the rearrangement of the ether to alkyl phenols is observed [21]. Yadav and Kumar have recently studied the kinetics of phenol cyclohexylation catalyzed by different solid acids, which catalyze the formation of phenyl cyclohexyl ether and the products of ring alkylation in a ortho-para ratio close to 2 [14]. The mechanistic aspect of the electrophilic attack to the phenol is investigated from a theoretical point of view by Tang and coworkers. These authors suggested that the addition of the sulfonic acid to the olefins occurs leading to the formation of a sulfonic ester intermediate, which, in turns, reacts with phenol to form the products of alkylation [31].

In this paper we study the cyclohexylation of some phenols and the reactivity of cyclohexyl phenyl ether in the presence of both $\mathrm{CH}_{3} \mathrm{SO}_{3} \mathrm{H}$ and sulfonic resins. In particular, we investigate the role of the cyclohexyl phenyl ether on the ortho-para selectivity and the reactivity of the dimethylphenols in order to account for the steric hindrance of the methyl groups on the electrophilic attack of the cyclohexyl cation.

\section{Experimental}

\subsection{Materials}

Reagents and solvents were used after purification of the commercially available samples and their purity was checked by the usual methods (melting point, TLC, HPLC, GC and GC-MS). The solvents were treated in a double bed column, filled with $\mathrm{H}_{2} \mathrm{SO}_{4} / \mathrm{SiO}_{2}$ and $\mathrm{SiO}_{2}$ to adsorb water and impurities. The residual water content was checked by HPLC analysis [32]. Commercial catalysts: macroreticular sulfonated styrene divinyl benzene resins Amberlyst $15^{\mathrm{TM}}$ and Amberlyst $36^{\mathrm{TM}}$ (a trade mark of Rohm and Haas) were purchased from Aldrich.

\subsection{Reactions}

The reactions and the kinetic runs were performed in a stirred glass reactor thermostatted by a circulation bath at $358 \mathrm{~K}$, containing weighed samples of solvent, reagents and catalyst at autogenous solvent pressure (122 and $158 \mathrm{kPa}$ for 1,2 dichloroethane and benzene, respectively). In a typical experiment $10 \mathrm{~mL}$ of solution containing $10 \mathrm{mmol}$ of phenol, $10 \mathrm{mmol}$ of cyclohexene plus $5 \mathrm{mmol}$ of methylcyclohexane as internal standard and the desired amount of catalyst $(100-500 \mathrm{mg})$ were placed in the reactor. All the operations were carried out into a glove box in order to minimize catalyst deactivation by air moisture. Small amounts of the solution were drawn at different times and the samples were analyzed by GC, and GC-MS using a HP5 capillary column (300 $\mu \mathrm{m}$ i.d. $30 \mathrm{~m}$ long, 95\% methyl, 5\% phenyl silicone phase). The samples were checked also by HPLC using a Perkin Elmer apparatus and a Lichrosphere 100 (RP-18, $5 \mu \mathrm{m}$ ) column. The first derivative at time 0 of a third order polynomial function, obtained by fitting cyclohexene concentration $v$ s. time at $10 \%$ of conversion, gave the initial rate of reaction.

For a reliable comparison of the performances of different catalysts it is essential to known if reaction rate data are affected by diffusion phenomena. This is verified by studying the influence of the granulometry and of the catalyst amount on the reaction rate catalyzed by the most active catalyst (Amberlyst 36 ) at $373 \mathrm{~K}$. The experimental evidences suggest that the kinetics is not influenced by diffusion phenomena, since there are no differences in the initial rate using resins with different granulometry and the initial reaction rates are strictly proportional to the catalyst amount. In addition, the inspection of Carberry and Wheeler-Weisz numbers shows values lower than 0.1 and 0.4 , respectively [33].

\section{Results and discussion}

\subsection{Influence of solvent and catalyst on reaction rate, conversion and selectivity}

Table 1 reports the activity of two sulfonated resins in the alkylation of phenol. Maximum yield, as reported in Table 1, is comprised between 20 and $26 \%$ at $40-50 \%$ of conversion. Despite of Amberlyst 36 promotes a initial rate of reaction higher than that of Amberlyst 15 , the latter gives the highest yield in the ether. As a matter of fact, Amberlyst 36 (5.5 meq. $\mathrm{H}^{+} \mathrm{g}^{-1}$ cat) shows a higher activity than the Amberlyst 15 (4.7 meq. $\mathrm{H}^{+} \mathrm{g}^{-1}$ cat), this is likely due to the higher acid content of the former. In fact, the activities of the two catalysts are quite similar considering the initial turnover frequency referred to the whole $\mathrm{H}^{+}$sites (Table 1 ). $\mathrm{CH}_{3} \mathrm{SO}_{3} \mathrm{H}$ (in homogeneous phase) is the least active catalyst and its TOF is 20 times lower than that of the sulfonic resins, likely due to the higher acidity of the latter [34]. As a matter of fact, by considering $p$-toluensulfonic acid as simplified model for the sulfonic resins, the $\mathrm{p} K_{\mathrm{a}}$ of the $p$-toluensulfonic acids is $2.7 \mathrm{p} K_{\mathrm{a}}$ units lower than that of methanesulfonic acid ( -4.7 and -2 , respectively) [35]. In the presence of $\mathrm{AlCl}_{3}$ the reaction is faster, but the comparison of the activities of sulfonated resins, methanesulfonic acid (protic acids) and $\mathrm{AlCl}_{3}$ (Lewis acid) is cumbersome due to the different nature of the acid site. It is noticeable that the reactivity of the ortho and para positions of phenol is not influenced by the type of sulfonic resins employed. Ortho- and para-positions of the phenol show similar relative reactivity giving ortho-para ratio $\cong 2$ in either benzene or 1,2-dichloroethane. In contrast, a not negligible solvent effect seems to be played by nitromethane, since the initial reaction rates are almost one order of magnitude lower than those measured in benzene and 1,2-dichloroethane. In addition, the ortho-para ratio clearly diminishes $(o / p \cong 1.5)$, thus suggesting an influence of the solvent on the electrophilic attack [36].

Despite of the large difference of activity between $\mathrm{CH}_{3} \mathrm{SO}_{3} \mathrm{H}$ and $\mathrm{AlCl}_{3}$ in homogeneous phase, the reactions show a similar $o / p$ ratio (4.2 and 4.5), thus suggesting similar relative reaction rate for each stage in this homogeneous reactions.

The concentration-time profiles reported in Figs. 1-3, relative to the reactions in the presence of Amberlyst $15, \mathrm{CH}_{3} \mathrm{SO}_{3} \mathrm{H}$ and $\mathrm{AlCl}_{3}$, respectively, show different trends. Fig. 1 reports the reaction catalyzed by Amberlyst 15. It appears that cyclohexyl phenyl ether is a transient species, which is almost completely consumed at the end of the reaction. On the contrary, the formation of cyclohexyl, 
Table 1

Alkylation of phenol: selectivity after $240 \mathrm{~min}$ of reaction at $358 \mathrm{~K}$. Run conditions: phenol $1.1 \mathrm{~mol} \mathrm{~L}^{-1}$, cyclohexene $1.1 \mathrm{~mol} \mathrm{~L}{ }^{-1}$, catalyst $400 \mathrm{mg}$, reaction volume $10 \mathrm{~mL}$.

\begin{tabular}{|c|c|c|c|c|c|c|c|c|c|}
\hline \multirow[t]{2}{*}{ Catalyst } & \multirow[t]{2}{*}{ Conv. (\%) } & \multirow[t]{2}{*}{$r_{0}{ }^{\mathrm{a}}$} & \multirow[t]{2}{*}{ TOF $^{\mathrm{b}}$} & \multirow{2}{*}{$\begin{array}{l}\text { Ether maximum } \\
\text { yield (\%) }\end{array}$} & \multicolumn{4}{|l|}{ Selectivity $^{\mathrm{c}}(\%)$} & \multirow{2}{*}{$\begin{array}{l}o / p \\
\text { Ratio }\end{array}$} \\
\hline & & & & & 2-Cyclohexyl phenol & 4-Cyclohexyl phenol & Dicyclohexyl phenols & Cyclohexyl cyclohexene & \\
\hline \multicolumn{10}{|l|}{ Benzene } \\
\hline Amb.15 & 42 & 15 & 5.3 & 25 & 29 & 16 & 13 & 15 & 1.9 \\
\hline Amb. 36 & 48 & 18 & 5.8 & 23 & 38 & 21 & 14 & 18 & 1.9 \\
\hline \multicolumn{10}{|c|}{ 1,2-Dichloroethane } \\
\hline Amb.15 & 51 & 18 & 6.8 & 26 & 29 & 14 & 15 & 12 & 2.0 \\
\hline Amb.36 & 64 & 22 & 6.9 & 23 & 31 & 16 & 18 & 15 & 1.9 \\
\hline $\mathrm{CH}_{3} \mathrm{SO}_{3} \mathrm{H}^{\mathrm{d}}$ & 21 & 3.5 & 0.34 & 17 & 10 & 2.4 & 2.3 & 2 & 4.2 \\
\hline $\mathrm{AlCl}_{3} \mathrm{~d}, \mathrm{e}$ & 44 & 58 & 7.7 & 15 & 5 & 1.1 & 4.6 & 1 & 4.5 \\
\hline \multicolumn{10}{|c|}{ Nitromethane } \\
\hline Amb.15 & 16 & 3.8 & 0.81 & 10 & 24 & 16 & Traces & Traces & 1.5 \\
\hline Amb.36 & 19 & 6.0 & 1.1 & 10 & 24 & 16 & Traces & Traces & 1.5 \\
\hline
\end{tabular}

a $\left(10^{5} \mathrm{~mol} \mathrm{~L}^{-1} \mathrm{~s}^{-1} \mathrm{~g}_{\mathrm{cat}^{-1}}{ }^{-1}\right)$.

b Initial turnover frequency $\left(10^{4} \mathrm{~s}^{-1}\right)$

c Products in trace amount, as the isomers of alkylated the cyclohexyl ether, has been neglected.

d Homogeneous reactions.

e $T 288 \mathrm{~K}, \mathrm{AlCl}_{3} 1 \mathrm{mmol}$.

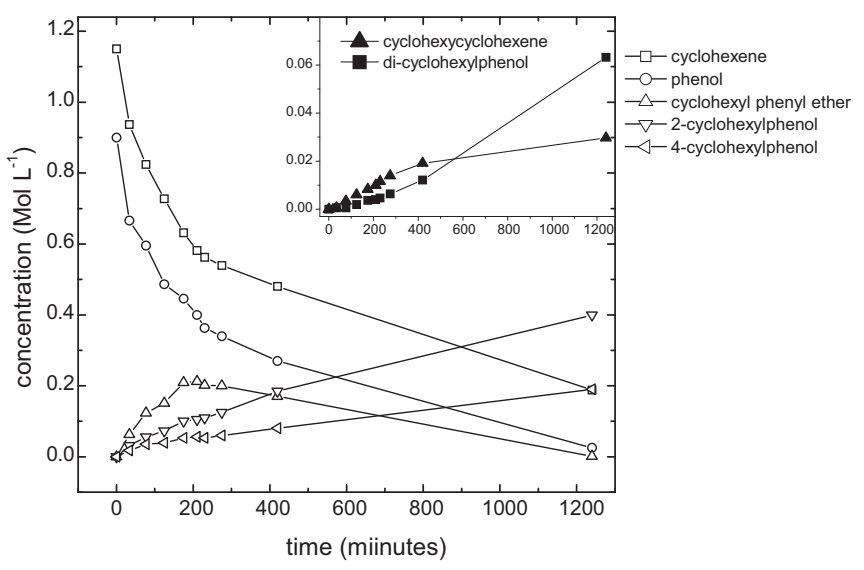

Fig. 1. Reaction profile of alkylation of phenol at $358 \mathrm{~K}$ catalyzed by Amberlyst 36. Run conditions: phenol $1.1 \mathrm{~mol} \mathrm{~L}^{-1}$, cyclohexene $1.2 \mathrm{~mol} \mathrm{~L}^{-1}$, catalyst $400 \mathrm{mg}$, solvent 1,2-dichloroethane, reaction volume $10 \mathrm{~mL}$.

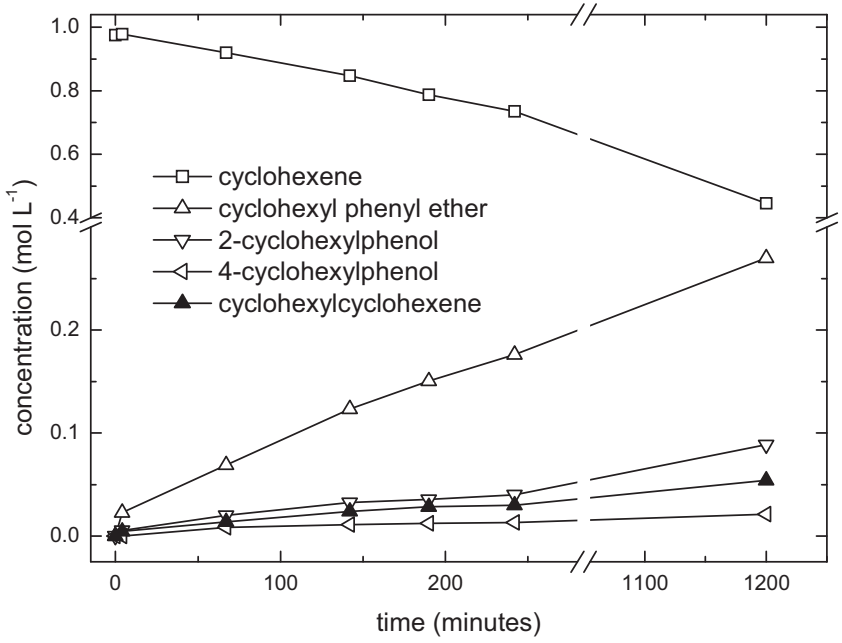

Fig. 2. Reaction profile of alkylation of phenol at $358 \mathrm{~K}$ catalyzed by methanesulfonic acid. Run conditions: phenol $1 \mathrm{~mol} \mathrm{~L}^{-1}$, cyclohexene $1 \mathrm{~mol} \mathrm{~L}^{-1}$, catalyst $400 \mathrm{mg}$, solvent 1,2-dichloroethane, reaction volume $10 \mathrm{~mL}$. di-cyclohexyl phenols increases monotonically during the reaction course. Formation of di-cyclohexyl phenols is observed also at very low conversion, because of alkyl phenols are highly activated toward the electrophilic attack [37]. Under the conditions used the main side reaction is cyclohexene dimerization, whose product (cyclohexylcyclohexene) shows an almost linear monotonic increase during reaction course. It is noteworthy that dimer formation is strongly inhibited using nitromethane as the solvent, suggesting an inhibiting effect of the solvent on the formation of the electrophile [36].

Fig. 2 shows the reaction profile in the presence of $\mathrm{CH}_{3} \mathrm{SO}_{3} \mathrm{H}$ : the reaction is almost ten time slower than that in the presence of Amberlyst 15 as a catalyst (Table 1 ) and after $20 \mathrm{~h}$ of reaction all the products are still increasing, while the formation of dicylohexyl phenols is negligible. The concentration-time profile of phenol cyclohexylation catalyzed by $\mathrm{AlCl}_{3}$ (Fig. 3) evidences a fast reaction also at $288 \mathrm{~K}$ (almost twice of that measured in the presence of Amberlyst 15 at $358 \mathrm{~K}$ ) but the reaction completely stops after $55 \mathrm{~min}$, with a modest conversion and with a noticeable loss of the mass balance. Such a behavior suggests a fast catalyst deactivation due to the formation of heavy pitch, which is confirmed by HPLC analysis.

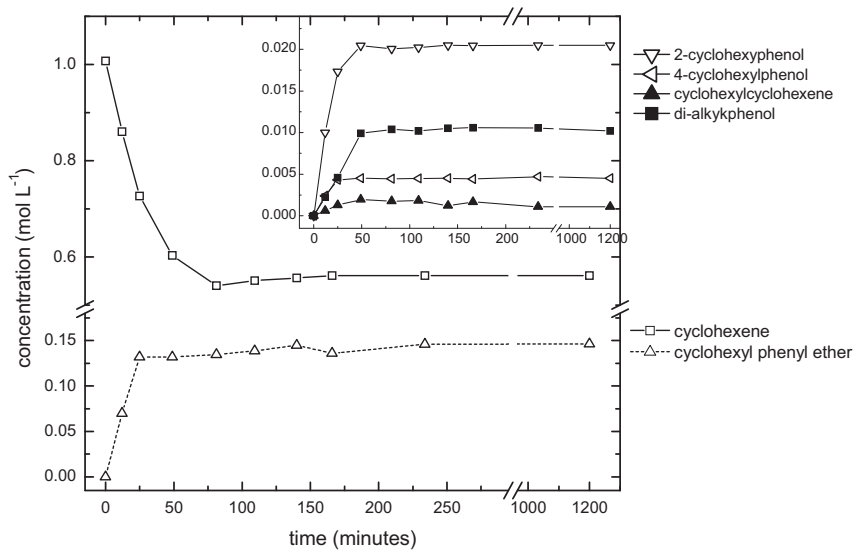

Fig. 3. Reaction profile of alkylation of phenol catalyzed by $\mathrm{AlCl}_{3}$ at $288 \mathrm{~K}$. Run conditions: phenol $1 \mathrm{~mol} \mathrm{~L}^{-1}$, cyclohexene $1 \mathrm{~mol} \mathrm{~L}^{-1}$, catalyst $140 \mathrm{mg}$, solvent 1,2 dichloroethane, reaction volume $10 \mathrm{~mL}$ 


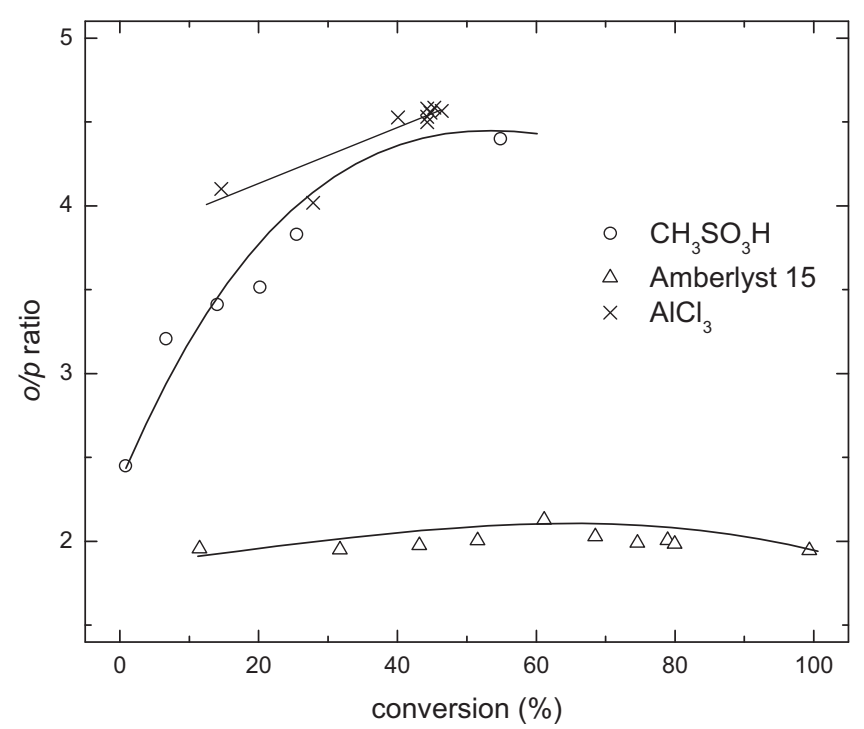

Fig. 4. Comparison of ortho/para ratio vs. conversion in the cyclohexylation of phenol in the presence of liquid and solid acid catalysts. Run conditions: cyclohexene and phenol $1 \mathrm{~mol} \mathrm{~L}^{-1}$, Amberlyst 15 and $\mathrm{CH}_{3} \mathrm{SO}_{3} \mathrm{H} 1.8$ meq $\mathrm{H}^{+}, \mathrm{AlCl}_{3} 10 \mathrm{mmol}$, solvent 1,2-dichloroethane, reaction volume $10 \mathrm{~mL}$ T $358 \mathrm{~K}$.

In Fig. 4 the trend of the ortho-para ratio vs. conversion for each catalyst is reported. Employing Amberlyst 15 as a catalyst ortho-para ratio remains practically constant (1.9-2.1), whereas, in the presence of $\mathrm{CH}_{3} \mathrm{SO}_{3} \mathrm{H}$, monotonically increases from 2.4 to 4.2 as the conversion increases. Also in the presence of $\mathrm{AlCl}_{3}$, the ortho-para ratio $v s$. conversion increases from 4.1 to 4.5 . These evidences suggest a different nature in the formation of the ortho and para isomers as the catalyst nature change. This is confirmed by the trends of the ortho-para ratio vs. cyclohexyl phenyl ether concentration reported in Fig. 5. Clearly, there is a linear relationship between the ether concentration and the formation of the ortho isomer in the presence of $\mathrm{CH}_{3} \mathrm{SO}_{3} \mathrm{H}$, thus suggesting the involvement of the cyclohexyl phenyl ether in the formation of the ortho isomer, likely via rearrangement $[37,38]$. On the contrary, in the presence of Amberlyst 15, there is a very small influence of the concentration of

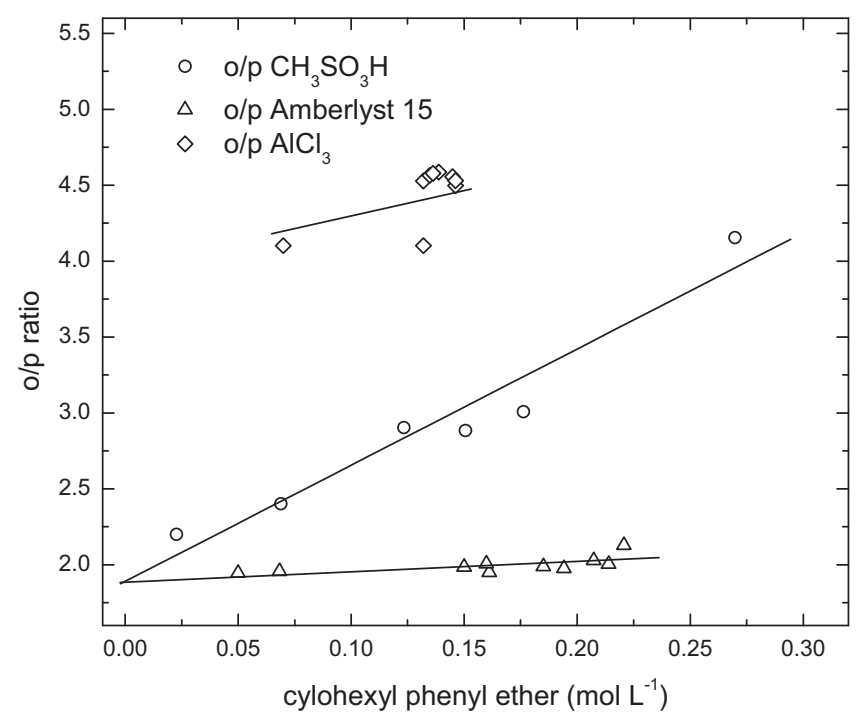

Fig. 5. Comparison of ortho/para ratio vs. cyclohexyl phenyl ether concentration in the cyclohexylation of phenol in the presence of liquid and solid acid catalysts. Run conditions: cyclohexene and phenol $1 \mathrm{~mol} \mathrm{~L}^{-1}$, Amberlyst $15,400 \mathrm{mg}, \mathrm{CH}_{3} \mathrm{SO}_{3} \mathrm{H}$ $1.8 \mathrm{meq} \mathrm{H}^{+}$and $\mathrm{AlCl}_{3} 1 \mathrm{mmol}$, solvent 1,2-dichloroethane, reaction volume $10 \mathrm{~mL} \mathrm{~T}$ $358 \mathrm{~K}$.

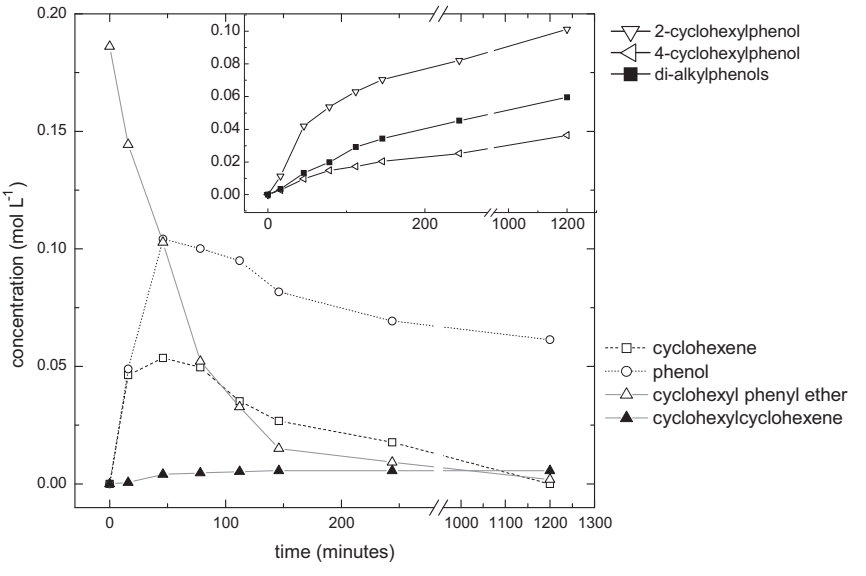

Fig. 6. Reactivity of cyclohexyl phenyl ether. Run conditions: T $358 \mathrm{~K}$ Amberlyst 15 , $400 \mathrm{mg}$, solvent 1,2-dichloroethane, reaction volume $10 \mathrm{~mL}$.

the cyclohexyl phenyl ether toward ortho and para selectivity. Such a behavior suggests that, in the presence of Amberlyst 15, the ortho and para selectivity is mainly influenced by the mesomeric effect of the hydroxyl group [37-39]. Besides the reaction catalyzed by $\mathrm{AlCl}_{3}$ shows a small increase of the ortho/para ratio vs. cyclohexyl phenyl ether concentration, but with a neat prevalence of the ortho isomer. The reasons of such a behavior are not clear and at least two effects may concur to give this result: the ether rearrangement and a specific interaction between phenol and $\mathrm{AlCl}_{3}$, as suggested by Sartori and coworkers [40].

\subsection{Reactivity of cyclohexyl phenyl ether}

The reactivity of cyclohexyl phenyl ether, in presence of acid catalysts, is reported in Figs. 6-8 and in Table 2. Fig. 6 shows the concentration-time profile of the reaction catalyzed by Amberlyst 15: cyclohexene reaches a maximum after $2 \mathrm{~h}$ of reaction, and then it decreases to complete consumption. At the same time, phenol concentration reaches to a maximum and subsequently diminishes smoothly (almost to a plateau). As a matter of fact, phenol is less converted than cyclohexene because all reactions, such as alkylation, dialkylation and cyclohexene dimerization, concur to consume cyclohexene. The initial reaction rate of ether decomposition is comparable to that of the phenol cyclohexylation and

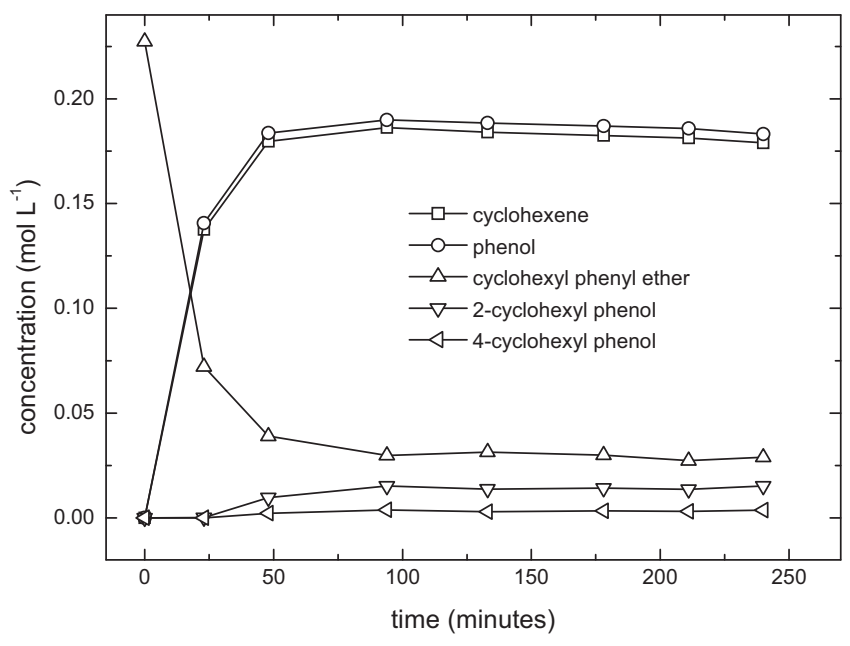

Fig. 7. Reactivity of cyclohexyl phenyl ether. Run conditions: cyclohexyl phenyl ether $0.21 \mathrm{~mol} \mathrm{~L}^{-1}$, T $358 \mathrm{~K}, \mathrm{CH}_{3} \mathrm{SO}_{3} \mathrm{H} 180 \mathrm{mg}$, solvent 1,2-dichloroethane, reaction volume $10 \mathrm{~mL}$ 
Table 2

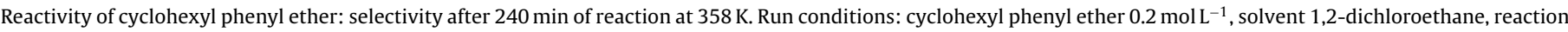
volume $10 \mathrm{~mL}$.

\begin{tabular}{|c|c|c|c|c|c|c|}
\hline \multirow[t]{2}{*}{ Catalyst } & \multirow[t]{2}{*}{ Conv. (\%) } & \multirow[t]{2}{*}{$r_{0}^{\mathrm{a}}$} & \multicolumn{3}{|l|}{ Selectivity (\%) } & \multirow{2}{*}{$\begin{array}{l}o / p \\
\text { Ratio }\end{array}$} \\
\hline & & & 2-Cyclohexyl phenol & 4-Cyclohexyl Phenol & Dicyclohexyl phenols & \\
\hline Amberlyst $15^{\mathrm{b}}$ & 92 & 10 & 10 & 33 & 18 & 3.3 \\
\hline $\mathrm{CH}_{3} \mathrm{SO}_{3} \mathrm{H}^{\mathrm{c}}$ & 85 & 40 & 4 & 0.9 & Traces & 4.2 \\
\hline $\mathrm{AlCl}_{3}{ }^{\mathrm{d}}$ & 74 & 75 & 19 & 3.4 & 22 & 5.6 \\
\hline
\end{tabular}

a $\left(10^{5} \mathrm{~mol} \mathrm{~L}^{-1} \mathrm{~s}^{-1} \mathrm{~g}^{-1}\right.$ cat $)$.

b Amberlyst $15,400 \mathrm{mg}$.

c $\mathrm{CH}_{3} \mathrm{SO}_{3} \mathrm{H} 180 \mathrm{mg}$.

d $T 288 \mathrm{~K}, \mathrm{AlCl}_{3} 0.2 \mathrm{mmol}$.

considering the whole reaction steps, ring alkylations are likely the slower stage, thus allowing accumulation of phenol and cyclohexene. In the presence of $\mathrm{CH}_{3} \mathrm{SO}_{3} \mathrm{H}$ (Fig. 7) the reverse etherification occurs with an initial reaction rate 4 times higher than when Amberlyst 15 is used as a catalyst, and after $50 \mathrm{~min}$ of reaction $75 \%$ of cyclohexyl phenyl ether is converted to cyclohexene and phenol in $95 \%$ of overall selectivity. In fact, $\mathrm{CH}_{3} \mathrm{SO}_{3} \mathrm{H}$ as a catalyst does not give ring alkylation products in high yields, but allows fast decomposition of the ether. Fig. 8 shows the concentration-time profile of the reactivity of the cyclohexyl phenyl ether at $288 \mathrm{~K}$, in the presence of $\mathrm{AlCl}_{3}$, the initial reaction rate is much higher than in the presence of Amberlyst 15 ( 7 times) but it does not reach completeness probably because of catalyst poisoning, in agreement to what found in phenol alkylation. In this case, the concentration of cyclohexene is negligible with respect to that of phenol, due to a fast formation of cyclohexene oligomerization products, which are probably one of the reasons of catalyst deactivation.

The ortho/para selectivity (see Table 2 ) with different catalysts after $4 \mathrm{~h}$ of reaction is in the range 3.3-5.6, and, as expected, the ether favors the ortho-selectivity. Apparently, the trends of the $o / p$ ratio vs. ether conversion, showed in Fig. 9, are not in agreement with those found in the phenol cyclohexylation (Fig. 5), because both $\mathrm{AlCl}_{3}$ and $\mathrm{CH}_{3} \mathrm{SO}_{3} \mathrm{H}$ show a constant o/p ratio (5.3, 4.3, respectively), while in the presence of Amberlyst 15 the $o / p$ ratio decreases from 4.2 to 2.7. Despite of the complexity of the reaction it is clear that cyclohexyl phenyl ether is involved in the selectivity of the ortho and para isomers of the alkylated phenols, but further investigations needs to highlight such a behavior.

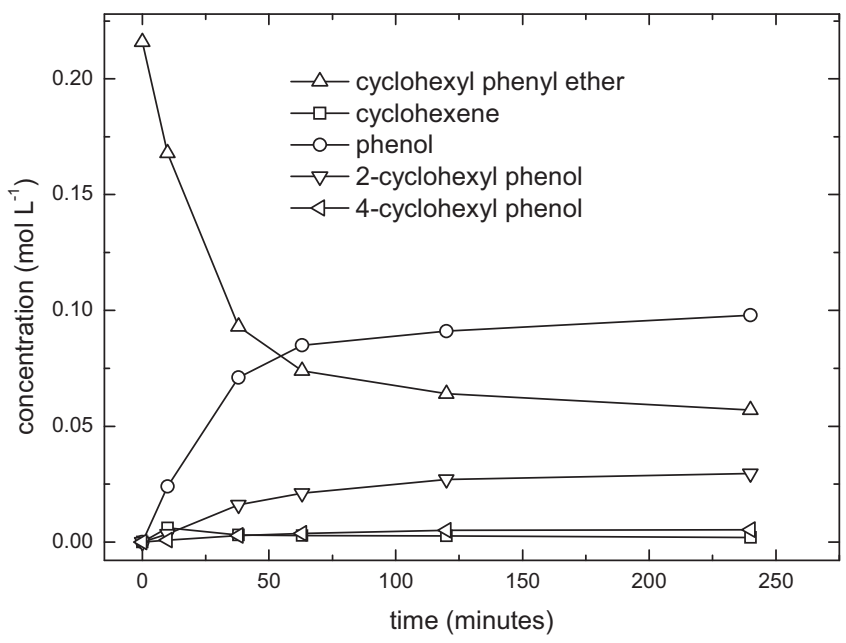

Fig. 8. Reactivity of cyclohexyl phenyl ether. Run conditions: cyclohexyl phenyl ether $0.21 \mathrm{~mol} \mathrm{~L}^{-1}$, T $358 \mathrm{~K}, \mathrm{AlCl}_{3} 1 \mathrm{mmol}$, solvent 1,2-dichloroethane, reaction volume $10 \mathrm{~mL}$.

\subsection{Reactivity of dimethylphenols and 2,4,6-trimethylphenol}

Further insight on the reactivity of the cyclohexyl cation as electrophile toward phenols may be gained by studying the reactivity of dimethylphenols and of the 2,4,6-trimethylphenol, in order to test the influence of the methyl substituent both for its inductive effect as well as for the steric hindrance. In Figs. 10 and 11, the concentration-time profile of the cyclohexylation of the 2,3dimethylphenol catalyzed by both Amberlyst 15 and $\mathrm{CH}_{3} \mathrm{SO}_{3} \mathrm{H}$ are shown. The general trend observed in this case is similar for all phenols, thus suggesting the involvement of a same reaction path. In agreement with that observed for the phenol the activity of the Amberlyst 15 is, in any case, higher than that of $\mathrm{CH}_{3} \mathrm{SO}_{3} \mathrm{H}$ (Table 3), which is likely due to the superior protonation ability of the solid acid with respect to the liquid one [34,35]. The activity of 3,5dimethyl phenol and 2,6-dimethyl phenol are lower than that of neat phenol (Table 1 ), the phenomenon may be ascribed to the steric hindrance of the substituents, which slow down the electrophilic attack $[37,38]$. Such an effect is more pronounced on the initial reaction rate of the 2,6-isomer than the 3,5-one. The small increase of the reaction rate of the 2,3-dimethyl-phenol cyclohexylation with respect to that of neat phenol may be due to the inductive effect of methyl groups, even though the steric hindrance may play a non-negligible effect. In fact, the initial reaction rate of 2,4-dimethyl-phenol is equivalent to that of phenol, the reason of this behavior is not clear, but it might be ascribed to the

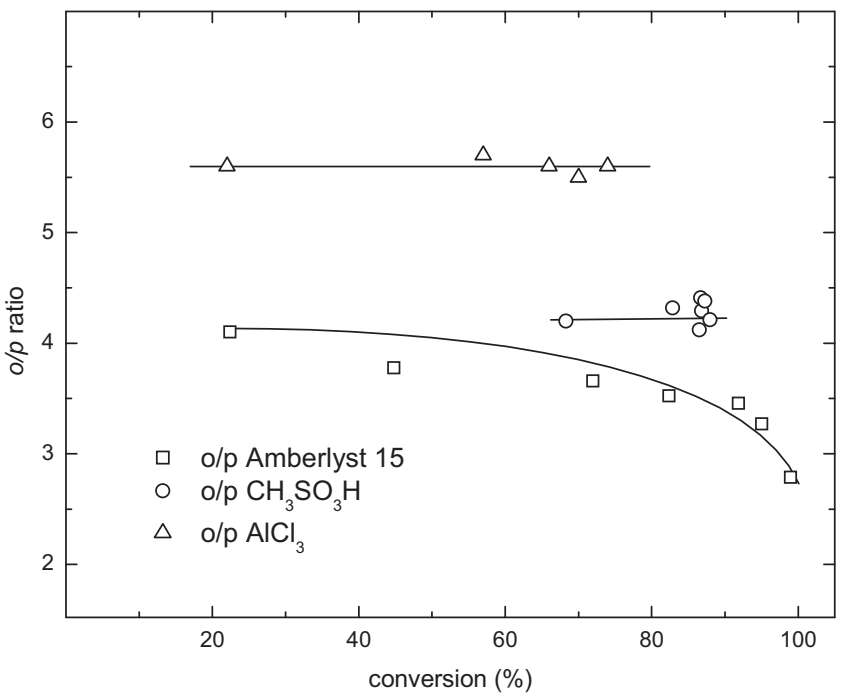

Fig. 9. Comparison of ortho/para ratio vs. conversion in the cyclohexylation of phenol and in the rearrangement of cyclohexyl phenyl ether. Run conditions: cyclohexene and phenol $1 \mathrm{~mol} \mathrm{~L}^{-1}$, Amberlyst $15, \mathrm{CH}_{3} \mathrm{SO}_{3} \mathrm{H} 1.8 \mathrm{meq} \mathrm{H}^{+}$and $\mathrm{AlCl}_{3} 1 \mathrm{mmol}$ as catalysts, solvent 1,2-dichloroethane, reaction volume $10 \mathrm{~mL} T 358 \mathrm{~K}$. Cyclohexyl phenyl ether rearrangement are carried out with the same run conditions except the initial concentration of $0.2 \mathrm{~mol} \mathrm{~L}^{-1}$. 
Table 3

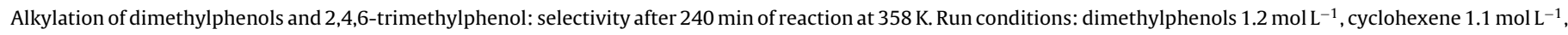
Amberlyst $15,400 \mathrm{mg}$ or $\mathrm{CH}_{3} \mathrm{SO}_{3} \mathrm{H} 180 \mathrm{mg}$, solvent 1,2-dichloroethane, reaction volume $10 \mathrm{~mL}$.

\begin{tabular}{|c|c|c|c|c|c|c|c|}
\hline \multirow[t]{2}{*}{ Catalyst } & \multirow[t]{2}{*}{ Conv. (\%) } & \multirow[t]{2}{*}{$r_{0}{ }^{a}$} & \multicolumn{5}{|c|}{ Selectivity (\%) } \\
\hline & & & Ether & 2-Cyclohexyl DMPb & 3-Cyclohexyl DMPb & 4-Cyclohexyl DMPb & $\begin{array}{l}\text { Cyclohexyl } \\
\text { cyclohexene }\end{array}$ \\
\hline \multicolumn{8}{|c|}{ 2,6-Dimethylphenol } \\
\hline Amberlyst 15 & 15 & 2.6 & 26 & - & 5 & 15 & 13 \\
\hline $\mathrm{CH}_{3} \mathrm{SO}_{3} \mathrm{H}$ & 7.2 & 0.9 & 18 & - & 11 & 16 & 55 \\
\hline \multicolumn{8}{|c|}{ 3,5-Dimethylphenol } \\
\hline Amberlyst 15 & 35 & 16 & 24 & 27 & - & 5 & 10 \\
\hline $\mathrm{CH}_{3} \mathrm{SO}_{3} \mathrm{H}$ & 14 & 4.1 & 29 & 14 & - & 0.1 & 13 \\
\hline \multicolumn{8}{|c|}{ 2,3-Dimethylphenol } \\
\hline Amberlyst 15 & 95 & 44 & 4 & 38 & 5 & 12 & 4 \\
\hline $\mathrm{CH}_{3} \mathrm{SO}_{3} \mathrm{H}$ & 13 & 3.1 & 18 & 19 & - & 5 & 55 \\
\hline \multicolumn{8}{|c|}{ 2,4-Dimethylphenol } \\
\hline Amberlyst 15 & 80 & 30 & 10 & 42 & $10^{c}$ & - & 5 \\
\hline $\mathrm{CH}_{3} \mathrm{SO}_{3} \mathrm{H}$ & 12 & 2.1 & 12 & 10 & $2^{c}$ & - & 62 \\
\hline \multicolumn{8}{|c|}{ 2,5-Dimethylphenol } \\
\hline Amberlyst 15 & 57 & 14 & 16 & 16 & - & 16 & 2 \\
\hline $\mathrm{CH}_{3} \mathrm{SO}_{3} \mathrm{H}$ & 16 & 1.5 & 16 & 9 & - & 4 & 15 \\
\hline \multicolumn{8}{|c|}{ 2,4,6-Trimethylphenol } \\
\hline Amberlyst $15^{\mathrm{c}}$ & 1 & 0.2 & - & - & - & - & 50 \\
\hline $\mathrm{CH}_{3} \mathrm{SO}_{3} \mathrm{H}^{\mathrm{c}}$ & 5 & 0.6 & - & - & - & - & 50 \\
\hline
\end{tabular}

a $\left(10^{5} \mathrm{~mol} \mathrm{~L}^{-1} \mathrm{~s}^{-1} \mathrm{~g}_{\text {cat }}{ }^{-1}\right)$.

b $\mathrm{DMP}=$ dimethylphenol.

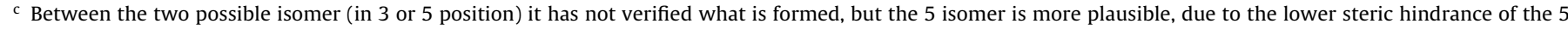
position.

${ }^{\mathrm{d}}$ Large part of the products are peach, formation of traces of the ether and the $\mathrm{m}$-isomer has been observed after $20 \mathrm{~h}$ of reaction.

simultaneous presence of two contrary effects: the steric hindrance and the inductive effect of the methyl groups. The reactivity of 2,5dimethyl-phenol is clearly influenced by the steric hindrance of the methyl groups, in particular the one in 2-positions slows down the attack of the cyclohexyl cation toward the hydroxyl group, while that in 5-position simultaneously hampers the attack to both ortho and para positions. As a matter of fact, 2,4,6-trimethyl-phenol shows a negligible reactivity toward electrophilic attack, thus suggesting the cyclohexyl cation is greatly influenced by the steric hindrance both on the attack to the hydroxyl group and to the phenyl ring.
The influence of the methyl groups on the ring alkylation selectivity is strictly related to the position of the substituent rather than their inductive effect. For instance, 3,5- and 2,3-dimethylphenol show, in the presence of Amberlyst 15 as a catalyst, an ortho-para ratio of 5.4 and 3.2, respectively. As a matter of fact, such a behavior suggests that the relative reactivity of the para positions of these compounds is about 3 times lower than the ortho ones. The comparison of these results with the almost equal relative reactivity of the ortho and para positions, observed in the cyclohexylation of phenol in the presence of Amberlyst 15 as a catalyst, suggests a strong effect of the steric hindrance of the methyl groups on the selectiv-

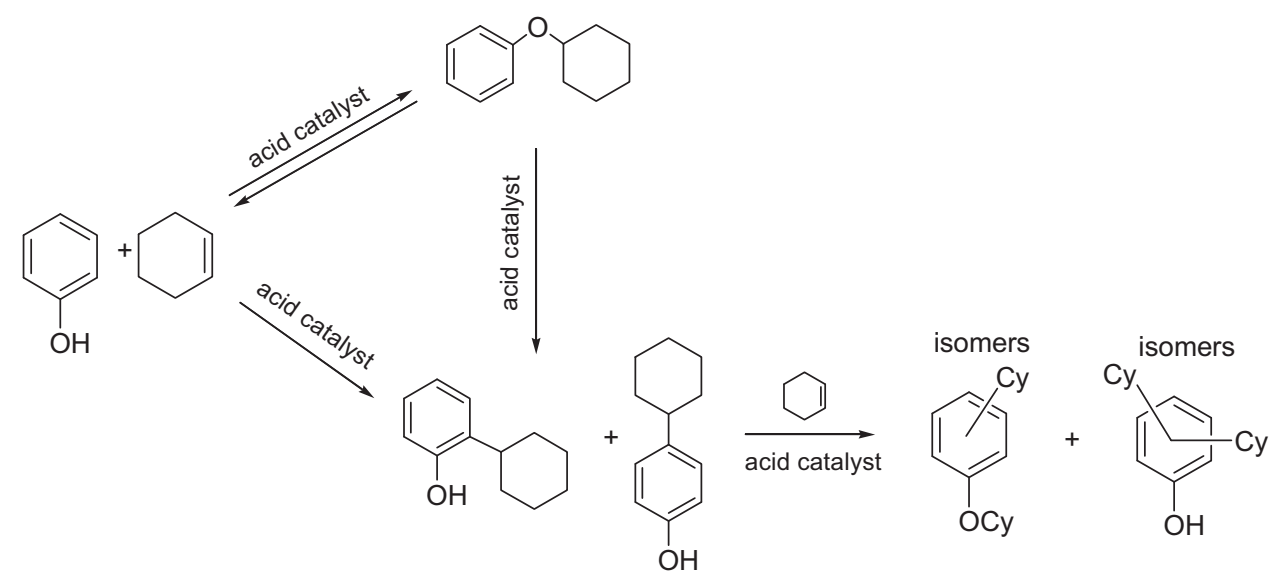<smiles>C1=C(C2CCCCC2)CCCC1</smiles>

Scheme 1. Reaction paths for phenol cyclohexylation and for the cyclohexene oligomerization. 


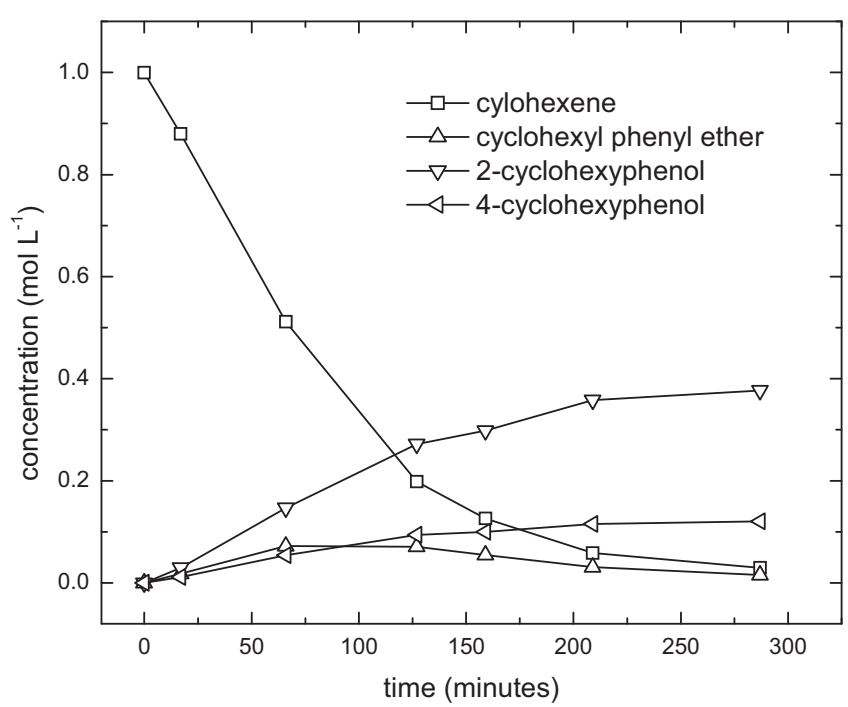

Fig. 10. Reactivity of 2,3-dimethyl phenol. Run conditions: $T 358 \mathrm{~K}$, solvent 1,2dichloroethane, Amberlyst 15, $400 \mathrm{mg}$, reaction volume $10 \mathrm{~mL}$.

ity. Further support to this is the equal reactivity of the ortho and para positions of the 2,5-dimethylphenol. In this case, it is likely that the methyl in 5-position has the same effect on the reactivity of the ortho and para position with the consequent equal relative reactivity.

When $\mathrm{CH}_{3} \mathrm{SO}_{3} \mathrm{H}$ is used the ortho selectivity increases as already observed for phenol. For instance, cyclohexylation of 3,5-dimethylphenol catalyzed by $\mathrm{CH}_{3} \mathrm{SO}_{3} \mathrm{H}$ shows an very high ortho-para ratio $(o / p=140)$ and in any case, for each phenol with unsubstituted ortho and para position, there is a neat increase of the ortho selectivity in the presence of $\mathrm{CH}_{3} \mathrm{SO}_{3} \mathrm{H}$ compared to Amberlyst 15 . Such a behavior is not straightforward, since it is not clear what are the reasons of such a specific ortho directing action of the $\mathrm{CH}_{3} \mathrm{SO}_{3} \mathrm{H}$, however, either the mechanism via cyclohexyl phenyl ether rearrangement [37-39], or that via a methanesulfonic-phenol complex [40] can be responsible for this behavior.

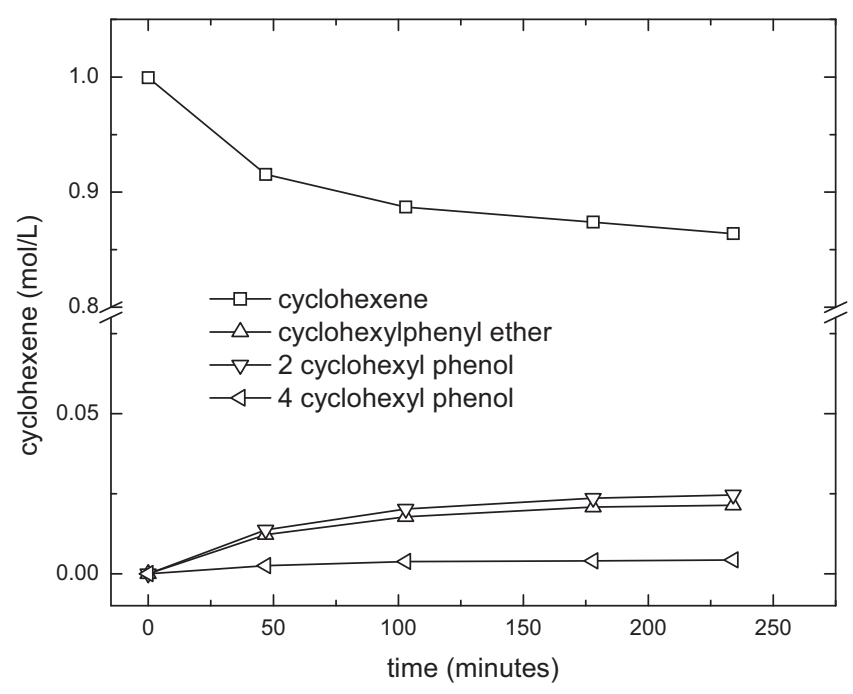

Fig. 11. Reactivity of 2,3-dimethyl phenol. Run conditions: $T 358 \mathrm{~K}$, solvent 1,2dichloroethane, $\mathrm{CH}_{3} \mathrm{SO}_{3} \mathrm{H} 180 \mathrm{mg}$, reaction volume $10 \mathrm{~mL}$.

\subsection{Reaction path proposed for the reactions}

Alkylation, etherification and olefin oligomerization are the reactions between phenols and cyclohexene observed in the presence of acid catalysts. All the experimental evidences suggest the reaction path depicted in Scheme 1. There are three parallel and two consecutive acid catalyzed reactions. In particular, the formation of cyclohexyl phenyl ether is reversible (also the formation of the aliphatic ether is reversible [41]), while ring alkylation of phenol, cyclohexene oligomerization cyclohexyl phenyl ether rearrangement and alkylphenols isomerization are practically irreversible [39].

\section{Conclusions}

The reaction between phenol and cyclohexene occurs via a complex path, which is characterized by the formation of the cyclohexyl phenyl ether as reversible intermediate and its complete conversion to the products of ring alkylation at the end of the reaction, whenever catalyst deactivation does not occur. The reactions of $\mathrm{O}-$ alkylation, ring alkylation, ether rearrangement and cyclohexene oligomerization occur simultaneously, but the latter is practically negligible by selecting the proper solvent or carrying out the reaction in excess of phenols. In the presence of Amberlyst 15 and 36 resins the selectivity of ring alkylation of phenol seems to be driven by the typical ortho/para orienting effect of the hydroxyl group. On the contrary, a specific action of homogeneous systems $\left(\mathrm{CH}_{3} \mathrm{SO}_{3} \mathrm{H}\right.$ and $\left.\mathrm{AlCl}_{3}\right)$ toward formation of the ortho isomers has been observed, but it is not clear what is the reason of such a behavior. The electrophilic attack of the cyclohexyl cation is strongly influenced by the steric hindrance of the methyl group as a matter of fact, the alkylation of 2,4,6-trimethylphenol practically does not occur, and the activation, due to the inductive effect to the contiguous positions of the methyl group, is negligible compared to the deactivation induced by the steric hindrance.

\section{Acknowledgments}

Financial support by Ca' Foscari University of Venice is gratefully acknowledged (Ateneo fund 2009). A thank to Dr. Davide Montin for some preliminary experiments carried out during his degree in Industrial Chemistry. Finally, a special thank to Mr. Claudio Tortato for the helpful discussions.

\section{References}

[1] K. Komiya, S. Fukuoka, M. Aminaka, K. Hasegawa, H. Hachiya, H. Okamoto, T. Watanabe, H. Yoneda, I. Fukawa, T. Dozono, in: P.T. Anastas, T.C. Williamson (Eds.), Green Chemistry: Designing Chemistry for the Environment, American Chemical Society, Washington, DC, 1996, p. 20.

[2] V.C. Malshe, E.S. Sujatha, React. Funct. Polym. 43 (2000) 183-194.

[3] A. Sato, I. Shimizu, E. Matsuzaka, US 4144279.

[4] M.A. Harmer, Q. Sun, Appl. Catal. A: Gen. 221 (2001) 45-62.

[5] W.F. Hölderich, G. Heitmann, Catal. Today 38 (1997) 227-233.

[6] A. Mitsutani, Catal. Today 73 (2002) 57-63.

[7] K.G. Chandra, M.M. Sharma, Catal. Lett. 19 (1993) 309-317.

[8] H. Zhang, S.M. Mahajani, M.M. Sharma, T. Sridhar, Chem. Eng. Sci. 57 (2002) $315-322$.

[9] A. de Angelis, C. Flego, P. Ingallina, L. Montanari, M.G. Clerici, C. Carati, C. Perego, Catal. Today 65 (2001) 363-371.

[10] R.A. Rajadhyaksha, D.D. Chaudhari, Ind. Eng. Chem. Res. 26 (1987) 1276-1280.

[11] R.H. Rosenwald, Alkylation in Kirk Ohtmer Encyclopedia of Chemical Technology, vol. 2, Wiley, 1978, p. 50.

[12] H.W.B. Bird, Alkylphenols in Kirk Ohtmer Encyclopedia of Chemical Technology, vol. 2, Wiley, 1978, p. 73.

[13] G.D. Yadav, S. Ganesh, Pathre, Ind. Eng. Chem. Res. 46 (2007) 3119-3127.

[14] G.D. Yadav, P. Kumar, Appl. Catal. A: Gen. 286 (2005) 61-70.

[15] N. Bhatt, A. Patel, J. Mol. Catal. A: Chem. 264 (2007) 214-219.

[16] R. Anand, K.U. Gore, B.S. Rao, Catal. Lett. 81 (2002) 33-41.

[17] R. Amandi, K. Scovell, P. Licence, T.J. Lotz, M. Poliakoff, Green Chem. 9 (2007) 797-801.

[18] G.D. Yadav, G.S. Pathre, J. Mol. Catal. A: Chem. 243 (2007) 77-84. 
[19] M.M. Sharma, React. Funct. Polym. 26 (1995) 3-23.

[20] A.J. Hoefnagel, H. van Bekkum, Catal. Lett. 85 (2003) 7-11.

[21] K. Wilson, D.J. Adams, G. Rothenberg, J.H. Clark, J. Mol. Catal. A: Chem. 159 (2000) 309-314.

[22] P.F. Siril, H.E. Cross, D.R. Brown, J. Mol. Catal. A: Chem. 279 (2008) 63-68.

[23] A. Akelah, A. Moet, Functionalized Polymers and Their Applications, Chapman and Hall, 1990.

[24] G.A. Olah, A.M. White, D.H. O’Brien, Chem. Rev. 70 (1970) 561-591.

[25] G.A. Olah, G.K. Surya Prakash, J. Sommer, Superacids", J. Wiley, 1985, p. 90.

[26] N.S. Isaacs, Physical Organic Chemistry, Longman, 1987, p. 395.

[27] Y. Tsuji, M.M. Toteva, H.A. Garth, J.P. Richard, J. Am. Chem. Soc. 125 (2003) 15455-15466.

[28] R. Klimkiewicz, H. Grabowska, H. Teterycz, Appl. Catal. A: Gen. 246 (2003) 125-136.

[29] B. Chaudhuri, M.M. Sharma, Ind. Eng. Chem. Res. 30 (1991) 227-231.

[30] E. Modrogan, M.H. Valkenberg, W.F. Hoelderich, J. Catal. 261 (2009) 177-187.

[31] Q. Ma, D. Chakraborty, F. Faglioni, R.P. Muller, W.A. Goddard, T. Harris, C. Campbell, Y. Tang, J. Phys. Chem. A 110 (2006) 2246-2252.
[32] B. Bjoerkqvist, H. Toivonen, J. Chromatogr. 178 (1979) 271-276.

[33] G.W. Roberts, in: P.N. Rylander, H. Greenfield (Eds.), Catalysis in Organic Synthesis, Academic Press, 1976, p. 1

[34] S. Kajount, B.M. Kierman, D.R. Brown, H.G.M. Edwards, J.A. Dale, S. Plant, Catal. Lett. 85 (2003) 33-40.

[35] N.C. Marziano, A. tommasin, C. Tortato, J. Chem. Soc. Trans. 2 (1991) 1575-1580.

[36] C. Reichardt, Solvents and Solvent Effects in Organic Chemistry, 2nd ed., VCH, Weinheim, 1988, p. 22.

[37] K. Schofield, Aromatic Nitration, Cambridge University Press, Cambridge, 1980.

[38] P.B.D. De La Mare, J.H. Ridd, Aromatic Substitution, Buttherworths Scientific Pubblications, London, 1959.

[39] C.B. Campbell, A. Onopchenko, D.C. Young, Ind. Eng. Chem. Res. 29 (1990) 642-647.

[40] G. Sartori, F. Bigi, R. Maggi, A. Arienti, J. Chem. Soc. Perkin Trans. 1 (1997) $257-260$

[41] J.F. Izquierdo, F. Cunill, M. Vila, M. Jhorra, J. Tejero, Ind. Eng. Chem. Res. 33 (1994) 2830-2835. 